\title{
Pharmacological Evaluation of Gentiana Kurroo Plant Extracts Against Alzheimer's Disease
}

\author{
Nasreena Sajjad ${ }^{1}$, Rohaya Alii ${ }^{1}$, Sumaya Hassan ${ }^{1}$, Seema Akbar ${ }^{2}$, Huma Habib ${ }^{3}$, Rabia Hamid ${ }^{1 *}$, Bashir \\ Ahmad Ganai*4 and Eijaz Ahmed Bhat*5 \\ ${ }^{1}$ Department of Biochemistry, University of Kashmir, 190006, Srinagar, India. \\ ${ }^{2}$ Regional Research Institute of Unani Medicine, Kashmir University Campus, Srinagar 190006, India \\ ${ }^{3}$ Islamia College of science and commerce \\ ${ }^{4}$ Centre of Research for Development, University of Kashmir, 190006, India. \\ ${ }^{5}$ Life science institute and school of medicine, Zhejiang University, Hangzhou, Zhejiang, 310058, P.R. China \\ *Corresponding author: Bashir Ahmad Ganai, Centre of Research for Development, University of Kashmir, 190006, India \\ Eijaz Ahmed Bhat, Life science institute and school of medicine, Zhejiang University, Hangzhou, Zhejiang, 310058, P.R. China \\ *Co-Corresponding author: Rabia Hamid, Department of Biochemistry, University of Kashmir, 190006, Srinagar, India
}

\section{ARTICLE INFO \\ Received: 慧 February 09, 2019 \\ Published: 靟 February 20, 2019}

Citation: Nasreena S, Rohaya A, Sumaya H, Seema A, Rabia H, Bashir Ahmad G, Eijaz Ahmed B. Pharmacological Evaluation of Gentiana Kurroo Plant Extracts Against Alzheimer's Disease. Biomed J Sci \& Tech Res 14(5)-2019. BJSTR. MS.ID.002620.

Keywords: Gentiana kurroo; Alzhemier disease; Scopolomine; Secondary metabolites; Mice
ABSTRACT

Alzhemier disease (AD) poses a major health concern with an ever-rising global burden. It is the common form of dementia in elderly people. The etiology of this disease is multifactorial. Many different hypothesis have been given from time to time to elucidate the causative factors of this disease, to explain the multifactorial nature of disease, such as cholinergic hypothesis, $A \beta$ hypothesis, tau hypothesis, oxidative stress hypothesis and inflammation hypothesis. Aging has been associated with oxidative damage and is extensive in the AD brain. Natural products and herbal remedies have been a source of many beneficial drugs. Plants have always been rich source of new anti-alzhemeric agents due to their extensive use in folk medicine. Hence, there arises a need to validate their folklore claims by various pre-clinical methods. The current study was designed to ascertain the neuroprotective potential Gentiana kurroo plant of Kashmir, which is used traditionally for treatment against various disorders. Qualitative phytochemical analysis demonstrated the presence of secondary metabolites like flavonoids in methanol and ethanol extracts followed by aqueous and ethyl acetate extracts. Maximum content of phenols was present in methanol extract followed by ethanol and ethyl acetate extracts. Furthermore, the effect of Gentiana kurroo on scopolamine-induced memory impairment in mice was studied via the elevated plus maze (EPM) test. The methanol extract of Gentiana kurroo extract when administered orally improved learning and memory of mice.

\section{Introduction}

Alzhemier's disease (AD) is one of the most common neurodegenerative disease. It is characterized by progressive neuronal loss and accumulation of proteins including extracellular amyloid plaques $(\mathrm{A} \beta)$ and intracellular tau tangles (neurofibrillary tangles, NFT) [1]. It is the major cause of dementia affecting millions of elderly people across the world [2]. An estimated 5.7 million Americans suffer from Alzheimer's dementia. By mid-century, the number of people living with Alzheimer's dementia in the United States is projected to grow to 13.8 million (Alzheimer's Association Report). According to World Health Organization (WHO) estimation, $71 \%$ of 81.1 million dementia cases will be reported by 2040 [3].
$\mathrm{AD}$ mainly targets the brain. It leads to impairment of cognitive function. In AD neurons finally get damaged. Furthermore, the neurons which are responsible to carry out basic bodily functions also get damaged [4]. The etiology of this disease is multifactorial [5]. Many different hypothesis have been given from time to time to elucidate the causative factors of this disease, in order to explain the multifactorial nature of disease, such as cholinergic hypothesis, $\mathrm{A} \beta$ hypothesis, tau hypothesis, oxidative stress hypothesis and inflammation hypothesis [6]. Currently only approved treatments by US Food and Drug Administration (FDA), includes five drugs that are used to treat the cognitive manifestations of AD. 
Acetylcholiesterae inhibitors AChEIs-rivastigmine (Exelon), galantamine (Razadyne, Reminyl), tacrine (Cognex), and Donepzil (Aricept) and NMDA receptor antagonist-memantine (Namenda) that target symptoms at its best [7]. Reminyl, Exelon and Aricept are effective in the early stages of treatment. Each drug has different mechanism of action and a different way to decrease the breakdown of acetylcholine which is an important neurotransmitter in the brain [8]. In AD there is a decreased level of this neurotransmitter. Memantine (Namenda) is the only drug which is shown to be effective at the later development of the disease $[9,10]$. To date, established treatments are only symptomatic in nature, trying to counterbalance the neurotransmitter disturbance of the disease. All the treatments suffer from various side effects [11]. Novel strategies have been developed to modify the disease process. In this regard major development is targeted to the $A \beta$ and tau-based therapeutics, which is a major key to unlock this disease soon [12]. New approaches to develop drugs for the treatment of $\mathrm{AD}$ that prevent free radical production and hence neurodegeneration, including AGE-inhibitors, antioxidants and anti-inflammatory substances are being emphasized [13]. The development of diseasemodifying drugs for AD is recognized as a worldwide necessity [14]

Natural products and herbal remedies have been a source of many beneficial drugs. About $80 \%$ of the world's population is dependent on plant-based medicines [15]. Herbal mixtures might have advantages as they have multiple target approach as compared with the single target. Herbal therapy can be a novel treatment option for AD. Phytotherapy may be a potential corner stone based on which treatment strategies can be streamlined [16] There is evidence which suggest that herbs or herbal formulations may provide complementary cognitive benefits to the approved drugs, however due to various methodological limitations, their use alone, it remains inconclusive. As many drugs are available today for treatment of $\mathrm{AD}$, various plant and their extracts are extensively employed in vivo models and AD patients. Herbal extracts produce a diverse range of natural products which includes alkaloids, indoles, phytosterols, isoflavonoids which exhibit complex pharmacological properties [17]. Plants provide wealth of bioactive compounds, which exert a substantial strategy for the treatment of neurological disorders such as Alzheimer's disease [18]. Plants with traditional knowledge of antioxidant and anti-alzhemeric activity have been studied [19].

Ethnomedicine is a promising field of research in Kashmir, as varied medicinal and aromatic plants including those used in curing various diseases, are grown in Kashmir. Gentiana kurroo belonging to family Gentianaceae and is a critically endangered (CR) medicinal plant species. It is endemic to the northwestern Himalayas. The rootstock of the plant is used in various ailments like fevers and urinary disorders. It is also used as a bitter tonic, antiperiodic, expectorant, antibilious, astringent, stomachic, antihelminthic, blood purifier, and carminative [20]. Several researchers have carried out experimental work to validate the folkloric use of the medicinal plant for different ailments like antibacterial, antioxidant, anti-arthritic, anti-inflammatory, analgesic activities and antidiabetic activity [21]. Present pharmacological study was to prove the activity of Gentiana kurroo extracts on Alzhemier's diseases. Results of various studies had shown that positive effect to treat the disease.

\section{Materials and Methods}

In this study, analytical grade chemicals were used and procured from standard commercial sources. Chloroform, sulphuric acid, ferric chloride, sodium hydroxide and Glacial acetic acid were purchased from Central Drug House (CDH). Picric acid, Methanol, Ethanol, Ascorbic acid, were obtained from Merk. Hydrochloric acid, Hexane and ethyl acetate were purchased from Rankem.

\section{Plant Material and Samples Preparation}

Gentiana kurroo was collected from Khrew, Kashmir and identified in the Centre of Plant Taxonomy (COPT) under Vocher No. 2466-KASH. The whole plant material was collected, dried and pulverized into coarse powder and extracted successively using hexane, ethyl acetate, methanol, ethanol respectively by soxhlet extraction. The solvents could evaporate in a rotary evaporator at $40 \stackrel{\circ}{\circ}-45^{\circ} \mathrm{C}$, and the extracts obtained were stored in a refrigerator at $4 \stackrel{\circ}{\circ} \mathrm{C}$. The plant extracts were solubilised in their respective solvents. The entire study was conducted using single batch of each plant extract to avoid batch-to-batch variation and maximize the product constancy.

\section{Phytochemical Screening}

Qualitative analysis of different phyto constituents in different plant extracts was done by various reported and standard methods [22].

\section{Effect of GKME on Scopolamine-Induced Memory Im- pairment in the Elevated Plus Maze (EPM) Test}

\section{Experimental Animals}

Animals: Swiss albino mice weighing 25-35g were used in this study. Animals were housed in plastic cages in groups. They had free access to food and water, and they were kept in a regulated environment $\left(23^{\circ} \mathrm{C}, 40-60 \%\right.$ humidity). Experiments were carried out between 9:00 am and 5:00 pm, in an experimental room with in the animal facility. All animal procedures were conducted in strict under the rules of ethical committee. The study was approved by the Ethical Committee of Kashmir University under Registration No. KU/2015/09, dated 21-08-2015.

\section{Acute Safety of Plant Extracts}

The effect of plant extracts on general behavior and safety was evaluated in mice according to Organization of Economic Co-operation and Development (OECD) Guideline No. 425. Mice of either sex (three females and three males) were administered with single doses of $2000 \mathrm{mg} / \mathrm{kg}$ of GKME orally by gavage. The animals were observed continuously for 4 hours after dosing, for any toxic symptoms. The number of survivors was noted after 24 
hours and the animals were kept under observation for further 13 days. Any changes in general behavior, weight, mortality or other physiological activities were observed.

\section{Dosage and Treatment}

Animals were divided into four groups each of six animals.

a) Group I: Control group oral administered by CMC (Carboxy methyl cellulose).

b) Group II: Animals oral administered by scopolamine hydro Chloride which is dissolved CMC (Negative control).

c) Group III: Animals oral administered by Donepzil.

d) Group IV: Animals oral administered by extract which is dissolved in CMC $(100 \mathrm{mg} / \mathrm{kg})$ and Alzheimer's induced with Scopolamine

e) Group IV: Animals oral administered by extract which is dissolved in CMC $(200 \mathrm{mg} / \mathrm{kg})$ and Alzheimer's induced with Scopolamine.

Elevated plus-maze served as the exteroceptive behavioral model to evaluate memory in mice. The procedures, technique and endpoint for testing memory were followed as per the parameters described by the investigators working in the area of psychopharmacology. The elevated plus maze for mice consisted of two open arms $(16 \mathrm{~cm} \times 5 \mathrm{~cm})$ and two covered arms $(16 \mathrm{~cm} \times 5 \mathrm{~cm} \times 12 \mathrm{~cm})$ extend from a central platform $(5 \mathrm{~cm} \times 5 \mathrm{~cm})$, and the maze was elevated to a height of $25 \mathrm{~cm}$ from the floor. On the first day (i.e. eighth day of drug treatment), each mouse was placed at the end of open arm, facing away from the central platform. Transfer latency (TL) was defined as the time (in seconds) taken by the animal to move from the open arm in to one of the covered arm with all its four legs. TL was recorded on the first day (training session) for each animal. The mouse could explore the maze for another 2 minutes and then returned to its home cage. Retention of this learned task (memory) was examined 24 hours after the first day trial (i.e. ninth day, 24 hours after last dose). Donepzil was used as positive control.

\section{Statistical Analysis}

All the experiments were performed in triplicates and the mean values \pm standard deviations (SD) are represented. Statistical differences between control and target groups for all experiments were determined using the analyses of variance (ANOVA). Statistical differences were considered significant at 'p' value less than 0.05 .

\section{Results}

\section{Phytochemical Screening of Gentiana Kurroo Extracts}

Gentiana kurroo also contained maximum phyto constituents in polar solvent extracts, as shown in Table 1. The results show the presence of maximum content of flavonoids in methanol and ethanol extracts followed by aqueous and ethyl acetate extracts. Maximum content of phenols was present in methanol extract followed by ethanol and ethyl acetate extracts. Saponins were present in all the extracts except aqueous extract. Hexane extract contained maximum amount of steroids whereas aqueous extract tested negative for steroids whereas rest of the extracts were negative for steroids. Terpenoids were found to be present in maximum amounts in methanol and ethanol extracts whereas other extract did not show the presence of terpenoids.

Table 1: Phytochemical analysis of different extracts of Gentiana kurroo.

\begin{tabular}{|c|c|c|c|c|c|}
\hline Phytochemicals & Hexane Extract & Ethyl acetate extract & Methanol extract & Ethanol Extract & Aqueous extract \\
\hline Flavonoids & - & + & +++ & +++ & ++ \\
\hline Phenols & - & ++ & +++ & ++ & - \\
\hline Saponins & + & + & + & + & - \\
\hline Steroids & ++ & - & - & - & - \\
\hline Terpenoids & - & - & ++ & ++ & - \\
\hline Alkaloids & - & - & ++ & ++ & - \\
\hline
\end{tabular}

\section{Acute Toxicity Study}

The effect of plant extracts on general behavior and safety was evaluated in mice. Mice of either sex (three females and three males) were administered with single doses of $2000 \mathrm{mg} / \mathrm{kg}$ of GKME orally by gavage. The animals were observed continuously for 4 hours after dosing, for any toxic symptoms. The number of survivors was noted after 24 hours and the animals were kept under observation for further 13 days. Any changes in general behavior, weight, mortality or other physiological activities were observed. In acute toxicity study, no adverse effects or mortality were observed after administration of single dose of $2000 \mathrm{mg} / \mathrm{kg}$ body weight of GKME
No adverse effects or mortality were observed after administration of single dose of $2000 \mathrm{mg} / \mathrm{kg}$ body weight of GKME. No behavioral changes were observed in mice during the entire period of experiment. However, taking into consideration the efficacy of any drug, lower doses up to $200 \mathrm{mg} / \mathrm{kg}$ body weight were selected for further in vivo studies.

\section{Effect of GKME on Scopolamine-Induced Memory Im- pairment in the Elevated Plus Maze (EPM) Test}

The elevated plus maze for mice consisted of two open arms $(16 \mathrm{~cm} \times 5 \mathrm{~cm})$ and two covered arms $(16 \mathrm{~cm} \times 5 \mathrm{~cm} \times 12 \mathrm{~cm})$ extend from a central platform $(5 \mathrm{~cm} \times 5 \mathrm{~cm})$, and the maze was elevated to 
a height of $25 \mathrm{~cm}$ from the floor. On the first day (i.e. eighth day of drug treatment), each mouse was placed at the end of open arm, facing away from the central platform. Transfer latency (TL) was defined as the time (in seconds) taken by the animal to move from the open arm in to one of the covered arm with all its four legs. TL was recorded on the first day (training session) for each animal. The mouse was allowed to explore the maze for another
2 minutes and then returned to its home cage. Retention of this learned task (memory) was examined 24 hours after the first day trial (i.e. ninth day, 24 hours after last dose). Significant reduction in the TL value of retention indicated improvement in memory. However, this decreased spontaneous alteration behaviour induced by scopolamine was significantly inhibited by GKME at $200 \mathrm{mg} / \mathrm{kg}$ (Figure 1 and Table 2).

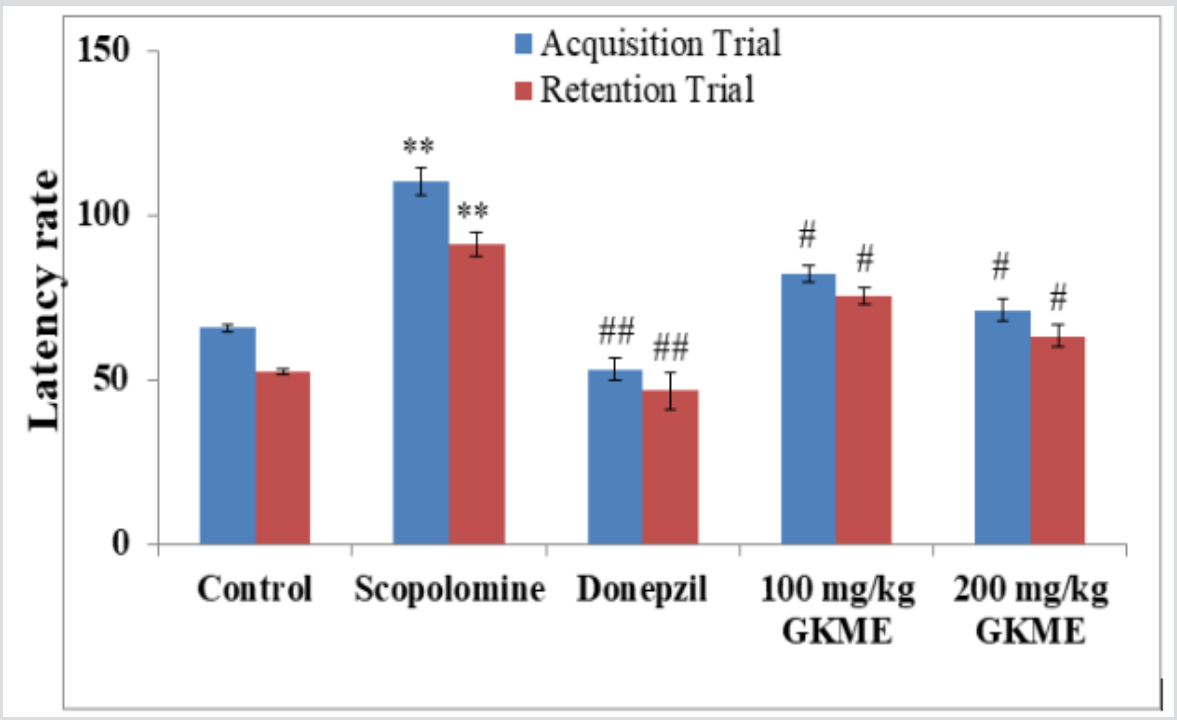

Figure 1: Effect of GKME on scopolamine-induced memory impairment in rats using the elevated plus maze (EPM) test. Data are expressed as mean latency time (s) \pm S.E.M. *Significant difference $\left({ }^{* *} \mathrm{P}<0.05\right.$ in comparison to the respective trial of the control group. \#Significant difference $\left(\#<00: 05\right.$ and $\left.{ }^{\# \#} \mathrm{P}<0: 01\right)$ in comparison to the scopolamine group.

Table 2: Effect of GKME on Transfer latency of mice using elevated plus maze.

\begin{tabular}{|c|c|c|c|}
\hline Group & Treatment & TL on $8^{\text {th }}$ day & ${\text { TL on } \mathbf{9}^{\text {th }} \text { day }}$ \\
\hline I & Control & $65.72 \pm 0.76$ & $52.45 \pm 0.73$ \\
\hline II & Scopolomine $(0.4 \mathrm{mg} / \mathrm{kg})$ & $110.40 \pm 2.42$ & $91 \pm 0.79$ \\
\hline III & Donepzil $(1 \mathrm{mg} / \mathrm{kg})$ & 53.25 & 46.51 \\
\hline IV & GKME $(100 \mathrm{mg} / \mathrm{kg})$ & $.82 .35 \pm 0.80$ & $46.51 \pm 0.76$ \\
\hline V & GKME $(200 \mathrm{mg} / \mathrm{kg})$ & $71.19 \pm 0.93$ & $63.24 \pm 0.60$ \\
\hline
\end{tabular}

\section{Discussion}

The present study demonstrated memory enhancing potential of GKME against scopolomine induced memory impairments. Scopolamine-induced amnesia has been used extensively to study the effect of compounds with propensity to be developed as therapeutic agents for dementia of AD type. Moreover, the cognitive impairment produced following scopolamine administration resembles the memory impairment seen in AD. Toxicology studies are very important to evaluate the safety of a drug in animals to decide if the drug could be safe for human use or not. Most of the plants and herbs used as food are also used in folk medicine for treatment against various ailments. These herbs are currently one of the main sources of drug discovery, but only few of them have been scientifically investigated for their toxic effects [23]. Acute toxicity studies in animals are important for any intended pharmaceutical use in humans. It is necessary for determining the safe doses. It could also be used to estimate the therapeutic index of drugs [24]. In current study, acute toxicity test was done to check if the administration of the methanol extracts of Gentiana kurroo (GKME) has any adverse effects on any parameter. The results of the study indicate no abnormal symptoms and no death of the tested rats. Change in body weight is regarded as an indicator of adverse effects of any drug $[25,26]$. The results revealed that single dose administration of GKME did not cause any significant changes in the general behavior and body weight of rats.

Scopolomine also known as levo-duboisine, and hyoscine, is an alkaloid drug with muscarinic antagonist effects. It is basically the secondary metabolite derived from plant from family Solanaceae (nightshade) family of plants. It act as a competitive antagonist at muscarinic acetylcholine receptors, specifically M1 receptor 
[27]. It is used as a standard drug for inducing amnesia in animals [28]. It affects behaviour, learning and memory. The exteroceptive behavioral model such as elevated plus maze was used to evaluate the learning and memory, whereas scopolamine being the natural ageing inducing amnesia served as interoceptive models [28]. Scopolamine significantly decreased the spontaneous aiteration behavior compared with control group. However this decreased spontaneous alteration behaviour induced by scopolamine was significantly inhibited by GKME.

\section{Conclusion}

The effect Gentiana kurroo on scopolamine-induced memory impairment in mice was also studied via the elevated plus maze (EPM) test. The methanol extract of Gentiana kurroo extract when administered orally improved learning and memory of mice. Alzheimer's disease is a neurodegenerative disorder currently without an effective treatment. Impairment of memory is the initial and most significant symptom of AD. AD is associated with a decline in cognitive abilities. In the present study, Gentiana kurroo extract $(100 \mathrm{mg} / \mathrm{kg}$ and $200 \mathrm{mg} / \mathrm{kg}$ ) administered orally improved learning and memory of mice assessed by the behavioral models like elevated plus maze.

\section{References}

1. Singh SK, Srivastav S, Yadav AK, Sri krishna S, Perry G (2016) Overview of Alzheimer's Disease and Some Therapeutic Approaches Targeting $\mathrm{A} \beta$ by Using Several Synthetic and Herbal Compounds. Oxid Med Cell Longev 2016: 7361613.

2. Anand R, Gill KD, Mahdi AA (2014) Therapeutics of Alzheimer's disease: past, present and future. Neuropharmacology 76: 27-50.

3. Ferri CP, Prince M, Brayne C, Brodaty H, Fratiglioni L, et al. (2005) Global prevalence of dementia: a Delphi consensus study. Lancet 366(9503): 2112-2117.

4. Kalaria RN, Maestre GE, Arizaga R, Friedland RP, Galasko D, et al. (2008) Alzheimer's disease and vascular dementia in developing countries: prevalence, management, and risk factors. Lancet Neurology 7(9): 812826.

5. Ramirez Bermudez J (2012) Alzheimer's disease: critical notes on the history of a medical concept. Arch Med Res 43(8): 595-599.

6. Kurz A, Perneczky R (2011) Novel insights for the treatment of Alzheimer's disease. Neuropsychopharmacol Biol Psychiatry 35(2): 373-379.

7. Mohandas E, Rajmohan V, and Raghunath B (2009) Neurobiology of Alzheimer's disease. Indian Journal of Psychiatry 51(1): 55-61.

8. Desai P, Shete H, Adnaik R, Disouza J, Patravale V (2005) Therapeutic targets and delivery challenges for Alzheimer's disease. World J Pharmacol 4(3): 236-264.

9. Onor ML, Trevisiol M, Aguglia E (2007) Rivastigmine in the treatment of Alzheimer's disease: an update. Clinical Interventions in Aging 2(1): 17-32.

10. Tampi RR, Van Dyck CH (2007) Memantine: efficacy and safety in mildto-severe Alzheimer's disease. Neuropsychiatric Disease and Treatment 3(2): 245-258.
11. Casey DA, Antimisiaris D, O’Brien J (2010) Drugs for Alzheimer's disease: Are They Effective? Pharmacy and Therapeutics 35(4): 208-211.

12. Aprahamian I, Stella F, Forlenza, OV (2013) New treatment strategies for Alzheimer's disease: is there a hope? The Indian Journal of Medical Research 138(4): 449-460.

13. Byun K, Yoo YC, Son M, Lee J, Jeong GB, et al. (2017) Advanced glycation end-products produced systemically and by macrophages: A common contributor to inflammation and degenerative diseases. Pharmacology \& Therapeutics 177: 44-55.

14. Yiannopoulou KG, Papageorgiou SG (2013) Currentand future treatments for Alzheimer's disease. Therapeutic Advances in Neurological Disorders 6(1):19-33.

15. Gurib FA (2006) Medicinal plants: Traditions of yesterday and drugs of tomorrow. Mol Aspects Med 27(1): 1-93.

16. Shao R, Xiao J (2013) Natural Products for Treatment of Alzheimer's Disease and Related Diseases: Understanding their Mechanism of Action. Current Neuropharmacology 11(4): 337.

17. Kennedy DO, Wightman EL (2011) Herbal Extracts and Phytochemicals: Plant Secondary Metabolites and the Enhancement of Human Brain Function. Advances in Nutrition 2(1): 32-50.

18. Obulesu M, Rao DM (2011) Effect of plant extracts on Alzheimer's disease: An insight into therapeutic avenues. J Neurosci Rural Pract 2(1): 56-61.

19. Yuan H, Ma Q, Ye L and Piao G (2016) The Traditional Medicine and Modern Medicine from Natural Products. Molecules 21(5): 559.

20.Singh A (2008) Phytochemicals of Gentianaceae: A review of pharmacological properties. Int J Pharm Sci Nanotechnol 1(1): 33-36.

21. Latif A, Khan TF, Afaq SH (2006) Anti-inflammatory activity of flower tops of Gentiana kurroo Royle extract. Pharmacologyonloine 3: 575-580.

22. Debiyi 00, Sofowora FA (1978) Pytochemical screening of medical plants. Iloyidia 3: 234-246.

23. Pereira WS, Ribeiro BP, Sousa AIP, Serra ICPB, Mattar NS, et al. (2010) Evaluation of the subchronic toxicity of oral treatment with Chenopodium ambrosioides in mice. Journal of Ethnopharmacology 127(3): 602-605.

24. Maikai VA, Kobo PI, Adaudi AO (2008) Acute toxicity studies of aqueous stem bark extract of Ximenia Americana. African Journal of Biotechnology $7(10)$ : 1600-1603.

25. Hilaly JE, Israili ZH, Lyoussi B (2004) Acute and chronic toxicological studies of Ajuga iva in experimental animals. Journal of Ethnopharmacology 91(1): 43-50.

26. Mukinda JT, Eagles PF (2010) Acute and sub-chronic oral toxicity profiles of the aqueous extract of Polygala fruticosa in female mice and rats. Journal of Ethnopharmacology 128(1): 236-240.

27. Malik J, Kaur J, Choudhary S (2018) Standardized extract of Lactuca Sativa Linn. and its fractions abrogate scopolamine-induced amnesia in mice: A possible cholinergic and antioxidant mechanism. Nutr Neurosci 21(5): 361-372.

28. Sharma D, Puri M, Tiwary AK, Singh N, Jaggi AS (2010) Antiamnesic effect of stevioside in scopolamine-treated rats. Indian Journal of Pharmacology 42(3): 164-167.

29. Ashwini G, Pranay P, Thrinath G, Karnaker Reddy T, Giri Prasad VS (2014) Pharmacological evolution of Marsilea Qudrifolia plant extracts against Alzheimer's disease. Int J Drug Dev \& Res 4(2): 153-158. 


\section{ISSN: 2574-1241}

DOI: 10.26717/BJSTR.2019.14.002620

Bashir Ahmad G, Eijaz Ahmed B. Biomed J Sci \& Tech Res

(C) This work is licensed under Creative Commons Attribution 4.0 License

Submission Link: https://biomedres.us/submit-manuscript.php

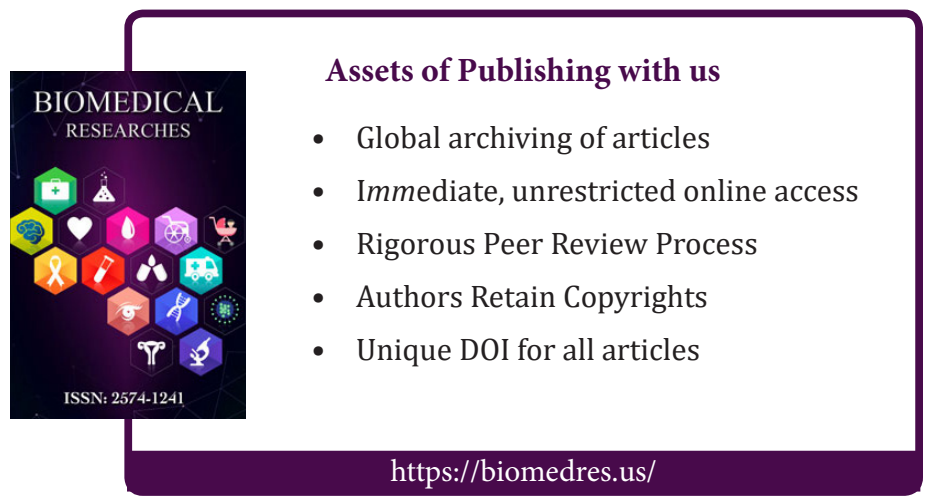

